\title{
DUAS LEITURAS DE A MAÇÃ NO ESCURO, DE CLARICE LISPECTOR: DA ABORDAGEM EXISTENCIAL, DE BENEDITO NUNES, AO CHAMADO SELVAGEM, DE EVANDO NASCIMENTO
}

\section{TWO READINGS OF A MAÇÃ NO ESCURO, BY CLARICE LISPECTOR: FROM THE EXISTENTIAL APPROACH, BY BENEDITO NUNES, TO THE WILD CALLING, BY EVANDO NASCIMENTO}

\author{
Fabrício Lemos da Costa* \\ UFPA
}

\section{Sílvio Augusto de Oliveira Holanda ${ }^{* *}$ UFPA}

Resumo: Este artigo tem como objetivo analisar a recepção crítica do romance A maçã no escuro, de Clarice Lispector (1920-1977), configurando-se em duas leituras distintas e particulares da narrativa, desenvolvida pelo crítico e filósofo Benedito Nunes (1995), em O drama da linguagem, e pelo crítico Evando Nascimento (2012), em Clarice Lispector: uma literatura pensante. Assim, abordaremos duas temáticas que se colocam como clave das leituras. Trata-se do dramático da linguagem e da peregrinação mística em Nunes e do chamado e da vocação selvagem em Nascimento. No trabalho interpretativo dos críticos, verificaremos como os autores encaminham as suas leituras, levantando questões e problemas no que tange à conjuntura da obra, em sua realização estética e temática.

Palavras-chave: A maçã no escuro. Clarice Lispector. Benedito Nunes. Evando Nascimento. Recepção crítica.

Abstract: This article aims to analyze the critical reception of the novel A maçã no escuro, by Clarice Lispector (1920-1977), configuring itself in two distinct and particular readings of the narrative, developed by the critic and philosopher Benedito Nunes (1995), in O Drama da linguagem, and by the critic Evando Nascimento (2012), in Clarice Lispector: uma literatura pensante. Thus, we will approach two themes that are the key to the readings. It is the dramatic of the language and mystical pilgrimage in Nunes, and

\footnotetext{
* Mestrando em Letras pela Universidade Federal do Pará (UFPA). ORCID: https://orcid.org/0000-0001-5578-8315. E-mail: $<$ fabricio.lemos1987@yahoo.com.br>.

** Doutor em Teoria Literária e Literatura Comparada pela Universidade de São Paulo (USP). Professor Associado da Faculdade de Letras e do Programa de Pós-Graduação em Letras (PPGL) da Universidade Federal do Pará (UFPA). ORCID: https://orcid. org/0000-0003-3971-9007. E-mail: <eellip@hotmail.com>.
} 
the wild calling and vocation in Nascimento. In the interpretive work of those critics, we will verify how the authors direct their readings, raising questions and problems regarding the conjuncture of the work, in its aesthetic and thematic realization.

Keywords: A maçã no escuro. Clarice Lispector. Benedito Nunes. Evando Nascimento. Critical reception.

\section{O CRIME E O PULO DE MARTIM}

O romance A maçã no escuro, de Clarice Lispector, publicado pela primeira vez em 1961, pela editora Francisco Alves, tem como acontecimento central a fuga de Martim, após uma suposta violência cometida contra a sua esposa. O homem, achando ter assassinado a mulher, foge, indo parar, inicialmente, em um hotel, para, em seguida, continuar o seu itinerário por meio de um pulo a um terreno terciário. Nessas andanças, após um longo período sozinho, exposto a um jardim antigo, encontra uma fazenda, passando a trabalhar para Vitória, dona do lugar. Nesses ambientes, Martim encaminha-se em emaranhados silêncios, emudecimento que o faz produzir (des)construções de si mesmo, mas, ao mesmo tempo, passa a intercruzar-se em longos movimentos dramáticos no que tange à linguagem. Noutra perspectiva, "chamados” são percebidos pelo sujeito como legítima conjectura de encontros com o selvagem, desde o jardim terciário até os currais do sítio de Vitória. O romance é dividido em três partes: "Como se faz um homem”, “Nascimento do herói” e “A maçã no escuro”, no qual este último dá título ao livro. Vejamos um trecho do romance que demonstra o início do itinerário e destino desse "herói” clariceano:

Esta história começa numa noite de março tão escura quanto é a noite enquanto se dorme. O modo como, tranquilo, o tempo decorria era a lua altíssima passando pelo céu. Até que mais profundamente tarde também a lua desapareceu.

Nada agora diferenciava o sono de Martim do lento jardim sem lua: quando um homem dormia tão no fundo passava a não ser mais do que aquela árvore de pé ou o pulo do sapo no escuro.

Algumas árvores haviam ali crescido com enraizado vagar até atingir o alto das próprias copas e o limite de seu destino. (LISPECTOR, 1961, p. 11).

Em suma, em A maçã no escuro, temos configurada a história de uma tentativa de assassinato, cujos fins são transpostos para "o trabalho com e sobre a linguagem” (MACHADO, 1989, p. 119). Para efeito deste “trabalho”, Martim deve passar por um longo itinerário, no qual se configura na vivência do homem junto à natureza, onde este passa a experimentar de qualquer coisa que caracteriza o selvagem, em sua mais genuína linguagem, isto é, dando-se pelas margens da mistura animal e das perdas de formas fixas humanas. Segundo Regina Machado, "Martim, em A maçã no escuro, tem também por tarefa um trabalho de construção: ele deve dar forma a uma vida de homem, a partir de uma perda originária de forma e de linguagem humanas” (MACHADO, 1989, p. 119). Portanto, no acontecimento inicial, a fuga, motivada por um crime, fê-lo transformar-se a partir da vivência de um modo de agir, andar e experimentar de comunicações outras, dadas em silêncio, mas carregadas de sinais: “A essa altura já se havia habituado à música estranha que de noite se ouve e que é feita da possibilidade de alguma coisa 
piar e da fricção delicada do silêncio contra o silêncio. Era um lamento sem tristeza. O homem estava no coração do Brasil. E o silêncio fruía a si mesmo” (LISPECTOR, 1961, p. 19).

Ao tentar escapar de uma suposta prisão, Martim, por vezes, esquece o crime cometido, tamanho o envolvimento que se arrola entre ele e a nova maneira comunicativa que advém do contato com o "mundo” natural e selvagem: “[...] em duas semanas aprendera como é que um ser não pensa e não se mexe e no entanto está todo ali” (LISPECTOR, 1961, p. 17). Faz-se mister perguntar-se, nesse sentido, quais os limites e o destino de Martim, sobretudo ao experimentar a "música estranha" e deixar de viver apenas pelo crime, para alargar-se em silêncio, levando-o “ainda mais longe” (LISPECTOR, 1961, p. 12). Consideramos, para efeito interpretativo, o presente romance um dos mais difíceis e perturbadores de Clarice Lispector, por tratar-se de um nascimento de um homem, dado como herói, e que surge como uma particularidade que envolve questões de ordem ética, o aniquilamento do outro, nesse caso, a esposa, para emergir o aparecimento de um outro Eu, que nasce de “despersonalizações” de si. O "nascimento” do homem, assim, configura a destruição de um outro, aquele antes do "pulo”, dado como burocrático, matemático e lógico, para emergir um novo, capaz de contemplar e comunicar-se sem linguagem humana.

Em síntese, indaga-se: o que Martim tornou-se? Como transfigurou o acontecimento em dramático jogo de linguagem? O que encontrou e como calou para melhor ser e viver em “latência”? São algumas perguntas de intérpretes consagrados, leitores de Clarice Lispector que ajudam a "desencalacrar" uma vivência tão particular, cujo movimento de construção heroica apenas tem sentido em margens de “deseroização”. Trata-se dos intérpretes Benedito Nunes e Evando Nascimento. Neste jogo de contribuição hermenêutica à narrativa clariceana, não queremos colocá-los em “juízos”, analisando as leituras como válidas ou inválidas, haja vista que estamos lidando com leitores consagrados e que muito contribuíram e contribuem para enriquecer a fortuna crítica de uma das nossas mais ilustres escritoras.

Assim, vale a pena ressaltar que Benedito Nunes, crítico e filósofo paraense, é um dos primeiros a publicar estudos específicos sobre a obra da escritora. Admirado por Lispector, construiu um importante monumento crítico com base na ficção clariceana, publicados em artigos e livros. Em livro, sua contribuição divide-se em: O mundo de Clarice Lispector (1966), Leitura de Clarice Lispector (1973) e O drama da linguagem: uma leitura de Clarice Lispector (1995). Em matéria de bibliografia obrigatória, Nunes é um nome essencial da recepção crítica de Lispector no Brasil, devendo ser revisitado sempre para fins de análise crítica, pois sedimentou uma leitura pela via hermenêutica de encontro entre a literatura e a filosofia, numa "transa" de contribuição que evidencia a linguagem da autora na clave do drama:

É o movimento de ir de uma a outra, portanto separadas, cada qual na sua própria identidade, sem que cada qual esteja acima ou abaixo de sua parceira, numa posição de superioridade ou inferioridade do ponto de vista do conhecimento alcançado ou da verdade divisada, que constitui aqui o essencial [...]. A relação transacional é uma relação de proximidade na distância. A Filosofia não deixa de ser Filosofia tornando-se poética nem a poesia deixa de ser poesia tornando-se filosofia. Uma polariza a outra sem assimilação transformadora. (NUNES, 2009, p. 29). 
Outro nome que tem se destacado na recepção crítica da escritora no Brasil é o escritor Evando Nascimento. Na crítica atual de Clarice, é um nome promissor, sobretudo por contribuir com novas perspectivas de leitura, envolvendo-se com uma ficção que chama de "literatura pensante”, que pode ser vislumbrado no próprio instrumental teórico que utiliza, como o francês Jacques Derrida e a sua perspectiva de desconstrução. Em livro, destaca-se Clarice Lispector: uma literatura pensante, publicado em 2012.

Vê-se que de 1966, ano de publicação do primeiro estudo em livro, de Nunes, até 2012, ano de publicação do livro de Nascimento, portanto, 46 anos, a fortuna crítica de Lispector alargou-se demasiadamente, tanto no Brasil quanto no exterior, tendo sido matéria de reflexão crítica em diversos dossiês de periódicos acadêmicos de muitos institutos e universidades (MEDEIROS, 2014, p. 52). Infelizmente, não nos ocuparemos desse monumento crítico, deixando-o para novas oportunidades. Entretanto, destacaremos, neste trabalho, uma parte importante dessa crítica, que ecoa do início da recepção, representada por Benedito Nunes, para pensarmos para a mais nova e também fundamental, que "atualiza” a ficção clariceana como a mais digna do pensamento.

\section{DOIS CRÍTICOS, DUAS LEITURAS}

Quando destacamos as leituras de críticos como Benedito Nunes e Evando Nascimento, prefiguramos em sentido histórico de recepção, interpretações que apresentam marcas que ora se comunicam, ora se afastam, em que temáticas são destacadas em um, ausentes ou não desenvolvidas em outro, levando-nos a novos "preenchimentos de vazios" da obra, para usar um conceito da Estética da Recepção de Wolfgang Iser. Para fins de destaque da leitura de um, interessamo-nos por esses "vazios" que preenchem e são capazes de elaborar uma nítida marca do leitor. Telma Vieira (2004, p. 26), utilizando-se desse manancial teórico em Clarice Lispector: uma leitura instigante, sublinha que, para Iser, “[...] a condição elementar no processo de interação texto-leitor são os 'vazios' que, preenchidos pelo leitor, garantem o sucesso no processo comunicativo". Todavia, em nosso trabalho, é imprescindível constatar que se trata de leitores históricos, portanto reais e que estão relacionados ao horizonte de leitura de Lispector.

Para esclarecer esse "leitor real", visto no seu momento histórico, vale a pena recorrermos a este breve fragmento de Hans Robert Jauss, importante nome da Estética da Recepção alemã, em A História da Literatura como Provocação à Teoria Literária: "A maneira pela qual uma obra literária, no momento histórico de sua aparição, atende, supera, decepciona ou contraria as expectativas de seu público inicial oferece-nos claramente um critério para a determinação de seu valor estético" (JAUSS, 1994, p. 31). Certamente, não estamos lidando com material crítico de primeira ordem, ou seja, das primeiras notícias críticas sobre o romance aqui estudado, mas sabemos que A maçã no escuro não é o primeiro livro de Lispector, revelando-nos que a escritora já tinha público e um horizonte de expectativa definido. De sorte, presenciamos e continuamos a lidar com a ficção clariceana como obra que se atualiza a cada nova leitura, pois novos estudos continuam a ser publicados, como revela Clarice Lispector: uma literatura pensante, de Evando Nascimento.

Destarte, A maçã no escuro, talvez uma das obras menos estudadas do conjunto ficcional de Clarice Lispector, continua a servir-nos como porta de entrada a este horizonte da prosa brasileira que a autora representa. Fica claro, nesse sentido, Benedito Nunes e Evando Nascimento, 
ao servirem de intérpretes ao romance, contribuem e “preenchem lacunas”, ecoadas na trajetória de Martim, auxiliando-nos em nossas próprias leituras, assim como revelando-nos a presença e a atualidade da obra. Nesse ínterim, perguntamo-nos: quais aspectos são evidenciados na leitura de cada crítico e como estas se comunicam ou se afastam para efeito de recepção?

\section{O MARTIM DE NUNES: ENTRE O REBELDE E O RELIGIOSO}

Destacamos, como foi dito anteriormente, a leitura de A maçã no escuro no livro O drama da linguagem: uma leitura de Clarice Lispector. Enfatizaremos o capítulo "A maçã no escuro ou o drama da linguagem”, o qual ecoa no título do livro, como fica evidente na palavra "drama”. Nesse sentido, o estudo de Nunes é dedicado a vários romances de Lispector, divididos entre os capítulos. Na seção dedicada ao texto A maçã no escuro, enfatizamos as seguintes ideias: De acordo com o crítico, Martim, após o crime cometido, passa a fugir duplamente, porque, nesse ato, a ação criminosa "[...] transforma-se num ato positivo de ruptura com a sociedade e a fuga, num movimento de evasão interior” (NUNES, 1995, p. 40). Dessa forma, vê-se que o herói, segundo Nunes, constitui-se como aquele que infringe um ato socialmente moral, sendo capaz de transfigurar-se positivamente para o encontro consigo mesmo. O estudioso, para isso, considera três etapas, arroladas nos três capítulos do romance. Vejamos:

As etapas correspondem às três partes do romance: a primeira "Como se faz um homem”, que sucede imediatamente ao divórcio com a sociedade, é a fase de isolamento interior completo, de plena solitarização da consciência, durante a qual o personagem, em meio aos rudes trabalhos do campo, reconhece a singularidade do seu ser individual; "Nascimento do herói”, é a fase da reconstrução de Martim como pessoa. [...], a terceira, "A maçã no escuro", no fim do romance, com a chegada dos policiais, em que a sanção, desagregando essa identidade postiça de herói, e anulando os efeitos de ruptura do delito, devolve o suposto criminoso ao convívio dos outros. (NUNES, 1995, p. 41, grifos nossos).

Da longa citação, enfatizamos três palavras que parecem convergir do ato do pulo, isto é, do "isolamento" de Martim, para, enfim, emergir do envolvimento "positivo”, como aborda Nunes, para o processo de "reconstrução" do homem. Assim, o verdadeiro Martim, como em cosmogonia heroica, nasce da "solitarização", quando começa a fazer-se como pessoa singular, não burocrática, tampouco "amarrada” às normas sociais. Indagamo-nos: como é possível essa “reconstrução”, ou, ainda, o que teria visto e presenciado Martim para chegar neste "interior”? Para Nunes (1995, p. 41), a imersão do sujeito na reconstrução de si mesmo apresenta um cunho ascético, místico e religioso, no qual o estudioso chama de “peregrinação simbólica da alma”, por vezes, este “[...] caráter místico, que vem juntar-se à imagem da revolta romântica - estampada na figura de Martim, rebelde e criminoso feito herói” (NUNES, 1995, p. 41). Nesse ínterim, quando o crítico interpreta o "transe" em Martim, é pela alcunha do místico sem palavras, ou seja, do silêncio em descortino que move o herói para a possibilidade de vislumbrar a sua vida pela via evangélica, manifestada em passagens como esta: "aquele que perde a sua vida, ganha a sua vida” (LISPECTOR, 1961, p. 152).

Em suma, são muitas as palavras que o autor utiliza para comungar de uma ideia místico-religiosa na vivência de Martim. Vocábulos como “júbilo”, “glória”, “conversão”, “evangélica”, 
“espiritual”, “fé”, “transcendente”, “expiar” e “culpa” parecem ter saído de um verdadeiro manancial bíblico, transplantado para o jogo hermenêutico de A maçã no escuro. Entretanto, ao lado da diversidade de palavras de teor religioso, Nunes elabora o fundamento interpretativo que o leva a considerar o romance em duas linhas. Trata-se da "romântica e da mística", evidenciadas e responsáveis por um desfecho, segundo ele, ambíguo, paradoxal e contraditório. Por um lado, Martim carrega um romântico espírito rebelde, liberador de si, das normas sociais; por outro, transpõe-se em conversão, pois caro é a linha que o liga à glória espiritual do "perder para ganhar”", postulado pela máxima do apóstolo Mateus. Vejamos um trecho que pode esclarecer tal posição crítica:

Como explicar que aquele homem esfrangalhado, desamparado, continuasse no entanto a ser aquela coisa a se olhar e a ser reconhecida até por olhos de criança: um homem, um homem com um futuro. A ressurreição, como fora prometida, se fizera. Desimportante como mais um milagre. Cuidadosamente discreta para não nos escandalizar. Exatamente como nós nos prometemos; e podeis deixar a nós a tarefa, e Deus é nossa tarefa, nós não somos a tarefa de Deus. Podeis deixar a nós a vida, oh nós bem sabemos o que fazemos! e com a mesma impassibilidade com que os mortos deitados sabem tão bem o que fazem. (LISPECTOR, 1961, p. 368).

Vê-se, dessa forma, que o itinerário de Martim produz-se numa vocação que o leva ao seu destino, afirmando-se singularmente em atmosfera espiritual, cujo sentido dá-se arrolado ao “metafísico e ético”, como sublinha Olga de Sá (2004, p. 119). Nesse ínterim, Martim carrega o exemplar arquétipo humano que, em tempos de rebeldia, se afirma também em "ética dura” (NUNES, 1995, p. 44), ao molde de São João da Cruz, como o faz lembrar Nunes, no momento da segunda fuga do personagem para A noite escuro, quando da aproximação da polícia para capturá-lo, devido ao crime cometido. Nunes (1995, p. 44) afirma ser um dos “topoi da via mística”. A obra oferece abertura para interpretações de caráter profundamente místico, dada a quantidade de vezes em que a palavra "Deus" aparece, assim como o vocábulo "silêncio". Além disso, o crítico paraense já havia realizado leituras que perpassam pelo horizonte do místico, como fez, por exemplo, em A Paixão Segundo G.H, romance publicado em 1964, pela Editora do Autor.

\section{MARTIM DE NASCIMENTO: DO CHAMADO SELVAGEM}

Como se dá no estudo de Benedito Nunes, Evando Nascimento não dedica um livro exclusivo para o romance A maçã no escuro, antes o mistura entre várias temáticas abordadas a partir do conjunto da obra da escritora. Para esta seção, dedicaremos uma breve reflexão das concepções conceituais com o fim de analisarmos a base da leitura da ficção clariceana por Nascimento, podendo ser vista em diversos romances e contos da autora. A primeira concepção diz respeito à ideia do chamado ao selvagem. De acordo com Nascimento:

Existe em Clarice uma nostalgia de não ter nascido e crescido bicho de todo [...]. Isso se configura no chamado, o apelo ou a vocação (em sentido etimológico: uma questão e voz, chamamento, intimação e convite) que sente vindo dos bichos. Ao

${ }^{1}$ Cf. Mateus, X, 39: “O que acha a sua alma, perdê-la-á: e o que perder a sua alma por mim, achá-la-á” (BÍBLIA SAGRADA, 2010). 
colocar sua temática animal na perspectiva do chamado, Clarice traz de volta certo recalque fundante de nossos valores culturais. (NASCIMENTO, 2012, p. 27).

O chamado, por vezes, evidenciado como vocação na literatura de Clarice, fê-la aproximar-se de uma particularidade animal e selvagem, cujas interseções configuram o saudoso sentimento de "ter nascido e crescido bicho". Para efeito de interpretação e contribuição, precisamos entender como essa "singularidade animal” implica a trajetória de Martim. É o que nos mostra Nascimento na seguinte passagem: "Em vez de soberano, o homem humano Martim, esse guerreiro de nascimento, se torna sujeito-objeto de uma experimentação animal e feminina, conduzida pelas vacas” (NASCIMENTO, 2012, p. 113). O acontecimento referido por Nascimento para caracterizar o animal em Martim dá-se no sítio de Vitória, quando o fugitivo é “chamado” pelas vacas do curral, num estado de mais autêntica latência, ambiente “quente e bom que pulsava como veia grossa” (LISPECTOR, 1961, p. 85). Nesse trecho, portanto, vemos como o crítico encaminha a sua leitura, revelando-nos um tom mais material, real e pulsante, como temos ainda no trecho seguinte: "Era a partir dessa larga veia que homens e bichos tinham filhos” (LISPECTOR, 1961, p. 85).

Destarte, por meio da perspectiva selvagem, o autor elabora uma leitura do conjunto da obra de Clarice Lispector com base na aproximação, o qual ele chama de chamado ou vocação, entre o homem e o animal. Como dissemos anteriormente, Nascimento não dedica um espaço, por exemplo, um capítulo inteiro, para tratar do caso exclusivo de A maçã no escuro, antes vai desenvolvendo uma análise a partir de várias narrativas, as quais dão conta de diversas temáticas por ele apresentadas, tendo como fundamento o que ele classifica como literatura pensante. Em relação ao aspecto selvagem na narrativa, vejamos uma passagem que ilustra essa interpretação:

E porque aquele homem parecia não querer nunca mais o pensamento nem para combater outro pensamento-foi fisicamente que de súbito se rebelou em cólera, agora que enfim aprendera o caminho da cólera. Seus músculos se comprimiram selvagemente contra a imunda consciência que se abrira ao redor da unha. Ilógico, lutava primitivamente com o corpo, torcendo-se numa careta de dor e de fome, $e$ com voracidade ele todo tentou se tornar apenas orgânico. (LISPECTOR, 1961, p. 40, grifos nossos).

Na seção “O erro de literatura”, sempre ao lado de outros romances de Lispector, o autor vai desenvolvendo algumas questões a respeito de A maçã no escuro com maior fôlego. Nascimento, pensando o caráter da literatura como "reflexão radical”, elabora uma pergunta: "A questão permanece a mesma: afinal, como escrever e publicar um livro questionador das convenções literárias como A maçã no escuro? A quem se destina?” (NASCIMENTO, 2012, p. 281). Coloca-se, aqui, neste bojo, as "políticas de interpretação”, envolvendo, por exemplo, a legitimidade de leituras e como são recepcionadas entre a crítica mais especializada.

Precisamos pensar um ponto importante, evidenciado pelo autor: o erro. Nunes, em seu Drama da linguagem, considera A maçã no escuro um romance de final paradoxal, ambíguo, e problemático, como dissemos, dado o seu caráter duplo, rebelde e religioso, tornando-o um livro sem desfecho. Nascimento, ao sublinhar sobre a presença de uma "literatura do erro", revela justamente a qualidade, dado o seu movimento "errôneo", numa perspectiva que se faz por marcas visíveis de “falhas” ou deixa um traçado "borrado” ao longo do romance. Ele afirma: 
A maçã no escuro é, em minha opinião, de que podem discordar outros leitores claricianos, junto com Água Viva e A descoberta do mundo, talvez o livro mais intenso de Clarice. Não que seja necessariamente o melhor, este é ponto, se se levar em conta somente a qualidade da realização literária. [...]. A maçã é um dos livros mais precários que conheço. (NASCIMENTO, 2012, p. 284).

No fundo, vemos que o mais importante é como vivenciamos e projetamos o nosso “olhar” para a obra. Nessa política de interpretação, a qualidade estética se revela naquilo que esperamos dela, de horizontes trilhados por outros romances publicados pela autora, ou, ainda, daquilo que faz dela um momento de rompimento, quem sabe, de erros, como já vem sendo apontado por outros críticos, como é caso de Sônia Roncador (2002) em seu livro Poéticas do empobrecimento: a escrita derradeira de Clarice Lispector.

No que tange ao chamado selvagem em A maçã no escuro, vale ressaltar que Nascimento na seção "Clarice e o não humano: rastros”, que poderia ser o momento oportuno, não menciona o romance para fins de análise da presença animal na trajetória de Martim; entretanto, pela própria organização de seu pensamento, vê-se que é possível alargar as tópicas desenvolvidas ao longo do estudo para vários textos da autora. De qualquer forma, é possível dizer que as evidências de uma animalidade podem ser vislumbradas na própria obra, como demonstra o trecho seguinte:

Naquele porão vegetal, que a luz mal nimbava, o homem se refugiava calado $e$ bruto como se somente no princípio mais grosseiro do mundo aquela coisa que ele era coubesse: no terreno rastejante a harmonia feita de poucos elementos não o ultrapassava nem ao seu silêncio. O silêncio das plantas estava no seu diapasão: ele grunhia aprovando. Ele que não tinha nada a dizer. E que não queria falar nunca mais. Ele que em breve deixara de ser uma pessoa. (LISPECTOR, 1961, p. 90, grifos nossos).

Nesse ínterim, a leitura da crítica de Evando Nascimento torna-se “iluminadora” para pensarmos a ficção de Lispector. Nela, várias temáticas são postas para defender a linha de pensamento que encara o texto como oportunidade para revelar o pensamento por meio da reflexão crítica das narrativas, como já explicamos.

\section{A MAÇÃ NO ESCURO E A CONTRIBUIÇÃO CRÍTICA DE NUNES E NASCIMENTO}

Comparativamente, Benedito Nunes dedica maior fôlego ao exame de A maçã no escuro. Nunes, como afirma Sônia Roncador (2002), desenvolve uma crítica de cunho mais existencialista. Segundo ela, “[...] críticos posteriores enfatizaram as afinidades entre seus trabalhos e outras formas narrativas modernas como o romance existencialista sobretudo a partir dos estudos de Benedito Nunes ainda na década de 60” (RONCADOR, 2002, p. 12). Recorrendo ao primeiro trabalho de Nunes, não é difícil percebemos a afirmação de Roncador. Pelo primeiro e segundo capítulo, “A Náusea” e “A Experiência mística”, respectivamente, vemos como a influência existencialista afirma-se neste estudo e mais tarde em outro livros. Na "Introdução" do livro de 1966, ele argumenta: 
Este ensaio é uma tentativa para interpretar coerentemente a ficção de Clarice Lispector, cuja importância cresceu muito, sobretudo depois do aparecimento de A Maçã no Escuro (1961). A Paixão Segundo G.H., de 1964, recebido pela crítica com respeitoso silêncio, quebrado por uma ou outra apreciação, ainda não foi devidamente avaliado quanto ao lugar que ocupa na prosa de ficção da extraordinária escritora. Houve mesmo, a propósito desse último romance de Clarice Lispector, reações de surpresa e de estarrecimento. Chegou-se até a falar no hermetismo da autora, de seu culto a vaguidão, e da incomunicabilidade final dos propósitos da romancista. [...]. Preocupamo-nos mais em caracterizar a atitude criadora da romancista, e a concepção-do-mundo, marcantemente existencialista, que com essa atitude se relaciona, do que em analisar a estrutura da criação literária propriamente dita. (NUNES, 1966, p. 11-12).

Benedito Nunes, o grande intérprete de Clarice Lispector, leu a ficção clariceana à luz do existencialismo, como demonstra a preocupação do estudo de 1966. O crítico, como fica evidente em outros trabalhos, influenciado pelo pensamento de Martim Heidegger, sobretudo quando da publicação de Passagem para o Poético - Filosofia e Poesia em Heidegger, de 1986, passou a envolver a sua crítica no que ele chamava de "transa" entre a filosofia e a literatura. $\mathrm{O}$ pensamento de Heidegger, por exemplo, já era usado para fins interpretativos em $O$ Mundo de Clarice Lispector (ensaio). Da mesma maneira, em "Introdução" ao livro Leitura de Clarice Lispector, de 1973, ele ressalta o caráter existencialista nas obras de Lispector: “[...] da obra de Clarice Lispector, não podem deixar de repercutir na concepção-do-mundo relacionada com a temática existencial que se projeta em diversos escritos da autora” (NUNES, 1973, p. XXI, grifo nosso).

Em tom de quase recomendação, Nunes traça e demarca a sua crítica, inserindo-a na história da recepção de Lispector no Brasil. Para isso, demonstra o desejo de uma interpretação existencialista nas introduções dos dois primeiros trabalhos do crítico. A ênfase no instrumental para ler os textos de Clarice Lispector parece constituir-se num projeto crítico de Nunes, como faz lembrar Olga de Sá: "Há, no projeto crítico de Benedito Nunes, uma evolução decidida já no último capítulo ‘Linguagem e Silêncio’ do seu primeiro ensaio, no sentido de caracterizar o movimento da escritura ficcional de Clarice Lispector” (SÁ, 1979, p. 57). Curiosamente, no mesmo estudo de Sá, a autora apresenta um breve texto de Clarice Lispector leitora, nesse caso, do filósofo, no qual afirma aprender sobre si mesma com o outro, o crítico: "Benedito Nunes, não é? Ele é muito bom. Ele me esclarece muito sobre mim mesma. Eu aprendo sobre o que escrevi” (LISPECTOR apud SÁ, 1979, p. 57).

Portanto, a leitura de A maçã no escuro, por Benedito Nunes, assume um projeto crítico, cujos alicerces estão arrolados, desde o seu primeiro ensaio, nas diretrizes do existencialismo. Nessa "lente” existencial, a literatura de Lispector ganhará força entre os leitores do Brasil e do mundo, o que é comprovado pela citação de Nunes entre diversos trabalhos acadêmicos. Superado ou não alguns pressupostos levantados, o crítico continua sendo lido, citado e estudado como intelectual de método bem projetado.

No romance, portanto, Nunes realça a perspectiva existencialista no itinerário de Martim, configurando-se em uma dupla trajetória, motivo de ambiguidade e paradoxo, ou seja, a rebelde romântica e a religiosa ascética. Vê-se que nessa dupla ação, o Ser prefigura como questão o 
envolvimento também da linguagem e seu drama: “[...] o caráter problemático da forma narrativa em A maçã no escuro, de que os enunciados modais são o indício, manifesta-se principalmente por uma temática da linguagem comum às duas linhas da ação, a romântica e a mística, que confluem no itinerário de Martim” (NUNES, 1995, p. 51, grifos do autor). Nesse ponto, a linguagem, como tema que traz no seu bojo o dramático na narrativa, manifesta-se, segundo Nunes, na "perda da linguagem", como evoca o discurso do narrador. Essa perda perfaz-se naquilo que o crítico considera como "solitarização", movimento este que tem um fundo místico, evangélico, marcado pelo silêncio e pela contradição. De acordo com Nunes:

O episódio da entrada no bosque em "noite escura", na terceira e última parte do romance, está em correspondência com a passagem do Sermão às Pedras. No sentido de uma temática da linguagem, que deixa em suspenso o alcance místico do incidente, a conversão religiosa, por que teria passado Martim nesse lugar, parece mais uma peripécia retórica. Quem antes se defrontara com a palavra crime, defronta-se agora com a palavra "salvação", que o empolga. (NUNES, 1995, p. 52 , grifo do autor).

Nessa citação, no entanto, temos presente o cerne da interpretação de Nunes. No que diz respeito à solidão, portanto, o silêncio de Martim ao longo da expiação e da animação em relação à possibilidade de salvação, vemos uma análise que corrobora o caráter místico. Como um herói santo no deserto, o homem entra numa verdadeira experiência meditativa que envolve a si mesmo e a linguagem, como defende Nunes:

Como a existência pessoal de Martim, que fracassa, também fracassa o dizer da narrativa. Todos os temas gerais, de ordem filosófica e religiosa - liberdade e ação, bem e mal, conhecimento e vida, intuição e pensamento, o cotidiano e as coisas, Deus e a existência humana - que aparecem entrelaçados na prática meditativa de A maçã no escuro - podem ser reduzidos a um só problema, latente ao itinerário do herói e à trajetória da própria narrativa, e que dá a esse romance uma latitude metafísico-religiosa: o problema do ser e do dizer. (NUNES, 1995, p. 57, grifos do autor).

A “latitude” metafísica fê-lo, em síntese, interpretar a narrativa de Lispector no interior de um projeto crítico que se alarga para a interpretação de todos os romances da escritora, segundo o existencialismo e suas questões. A temática do silêncio, "solitarização", da busca religiosa e mística, pois só podem estar implicadas no amálgama da metafísica e seus problemas filosóficos, transportados, em "transa", no jogo da contribuição entre o conhecimento advindo da filosofia para a literatura, e vice versa.

Mais recente é a crítica de Evando Nascimento, como tivemos oportunidade de argumentar anteriormente. Sua trajetória acadêmica parece evidenciar um imenso interesse pela produção ficcional de Clarice Lispector, trabalhando, principalmente com temáticas que se desenvolvem na aproximação dessa literatura com a Natureza, o selvagem, o Mal e o Erro. Nascimento, também professor universitário e autor de ficção, inaugurou a sua crítica de Lispector, quando já produzia um trabalho acadêmico de grande fôlego, a relação entre o pensamento de Derrida com a literatura, objeto de conclusão de um Doutorado, em 1995, mais tarde publicado em livro, em 1999, cujo o título é Derrida e a Literatura: "notas" de literatura e filosofia nos textos da 
desconstrução. Nesse livro, Nascimento já menciona um termo que utilizará para pensar a obra de Clarice. Trata-se da literatura pensante, imbuído pelas leituras de Derrida. Sobre as preferências desse intelectual francês, ele declara:

No plano da literatura, a preferência de Derrida se faz por autores como Celan, Ponge, Shakespeare, Joyce, Poe, Baudelaire, Genet, Kafka, Jabès... uma série em que Mallarmé não é certamente o menor deles. A escolha se justifica pelo tipo especial de literatura que praticaram: chamaria, por antecipação, uma literatura pensante. (NASCIMENTO, 1999, p. 22, grifo do autor).

O que ele chama de literatura pensante, nesse sentido, explica o seu interesse pela produção ficcional da autora, no qual emerge todas as temáticas mencionadas. Vale a pena ressaltar que o autor se encontra ainda em plena produção acadêmica, sendo inviável, portanto, uma reflexão fechada do seu pensamento. De sorte, sabemos o material instrumental teórico que utilizou até agora para elaborar a sua interpretação de romances, como A maçã no escuro. Desse instrumental, podemos pensar a maneira como o silenciar de Martim fê-lo aproximar-se ao grunhir selvagem. O fugitivo emudece para melhor contemplar, passando a comunicar-se com a natureza, em um movimento de mistura e entrega. Como aponta Nunes (1995, p. 43): "Martim está mais próximo da Natureza do que das mulheres da fazenda”. Contudo, indagamo-nos: como se dá essa aproximação, ou, ainda, como esse contato se alarga no modo de agir, andar e comunicar de Martim? Na interpretação de Nascimento, podemos encontrar algumas respostas interessantes, sobretudo em sua defesa, relacionando ao chamado ou vocação pelo animal, em que é possível "ouvir ecos" do livro O animal que logo sou, de Derrida, como fica evidente nesta passagem: “O que este animal é, o que ele terá sido, o que ele seria, quereria ou poderia ser, talvez eu o seja” (DERRIDA, 2002, p. 63).

Em suma, o romance é citado em vários momentos ao longo do estudo de Nascimento. Dessa forma, quando as temáticas de discussões são levantadas pelo crítico, mesmo quando a narrativa não é mencionada, parece ser tarefa do leitor associá-las como possibilidade de discussão a partir da temática em questão. Nesse caso, quando o "chamado” pelo selvagem é apresentado, o estudioso não se refere à narrativa, corpus específico de nosso trabalho; todavia, como já argumentamos, a possibilidade de incluí-lo é enorme, haja vista que a obra consegue corresponder a essa leitura a partir de diversos momentos do itinerário de Martim². O homem mistura-se à terra, privilegia o informe ${ }^{3}$ em determinadas situações. Em silêncio, aprova atos, grunhindo.

Nesse “chamado”, poder-se-ia encontrar uma explicação para o silêncio de Martim, que se imbrica entre o primário selvagem e o informe, quando não há palavra, sendo apenas grunhidos e latências: “[...] como se nenhum passo tivesse sido dado. Pois no escuro ele era agora apenas

\footnotetext{
${ }^{2}$ Enumeramos, aqui, vários trechos que comprovam esse chamado selvagem: "tinha agora todos os sentidos que tem um rato" (LISPECTOR, 1961, p. 102), “quando dormia, dormia. Quando trabalhava, trabalhava. Vitória mandava nele, ele mandava no próprio corpo. E algo crescia com rumor informe” (LISPECTOR, 1961, p. 103), "Na imundície penumbrosa havia algo de oficina e de concentração como se daquele enleio informe fosse aos poucos se apontando concreto mais uma forma” (LISPECTOR, 1961, p. 104), “pertencia agora ao curral” (LISPECTOR, 1961, p. 108), “O calor do corpo do homem e dos bichos se confundiu na mesma mornidão amoniacada do ar. O silêncio do homem automaticamente se transformara. Ele enfim ganhara uma dimensão que uma planta não tem” (LISPECTOR, 1961, p. 107).

${ }^{3}$ Em relação ao informe, é oportuno recorrermos, em nota, ao verbete “Informe” do filósofo francês Georges Bataille (2018, p. 147): "Termo que serve para desclassificar, exigindo geralmente que cada coisa tenha a sua forma. [...]. Em contrapartida, afirmar que o universo não se assemelha a nada e é apenas informe equivale a dizer que o universo é algo como uma aranha ou um escarro”.
} 
aquela coisa informe com um único sentimento primário. Num único pulo de recuo, ele de novo acabara de se afastar do território da palavra” (LISPECTOR, 1961, p. 243). Nascimento, contrapondo-se, em certa medida, à crítica existencialista, mesmo não negando o caráter religioso da existência de Martim, reclama um alargamento da reflexão, principalmente no que tange à perda da linguagem. Para ele:

Não vamos reduzir, evidentemente, A maçã no escuro a fábula moralista de teor cristão. A travessia de Martim e a perda da linguagem como corrosão da identidade são ganhos fundamentais para nossa literatura e para nossa cultura. As malhas da lei jamais conseguirão recuperar essa devastação da linguagem e seus clichês (da doxa, como diria Barthes, 1995), pois atos de Martim se inscrevem por meio da força de um pensamento singular. (NASCIMENTO, 2012, p. 271).

Temos, aqui, prefigurado a imensa contribuição de Evando Nascimento em torno da interpretação da ficção clariceana. De certo modo, ele nos permite "olhar" para o lado oposto de uma tradicional leitura, principalmente romanesca da autora, no qual um viés "menos metafísico" se configura. Ao atentar-se para a vocação ou chamado para com o animal, o crítico inaugura uma perspectiva que nos estimula novas interpretações de toda a obra de Lispector. Ainda sobre A maçã no escuro, ele considera que:

$\mathrm{O}$ assassinato da linguagem consensual para obrigar a repensar as relações entre inocência, infância, pecado, mal, maldade, mal do mal, pior, e o que daí decorre — tudo isso é irrevogável, tem força de lei, de outra lei, como lei da alteridade que está na base de todo pensamento intensivo. (NASCIMENTO, 2012, p. 271-272, grifo nosso).

O assassínio da linguagem, portanto, é o “efeito” de uma disposição para a alteridade, despertada em Martim quando do contato mais próximo, em solidão, com a Natureza. Assim, se aquele movimento de "solitarização", na qual considerou Benedito Nunes, leva-o a um itinerário meditativo, dividido entre as linhas rebelde e religiosa, sempre imbuído de uma evangélica oportunidade de salvação, em Nascimento, a solidão do herói, ao tornar-se "afásico", como pensa Olga de Sá (2004) no livro Clarice Lispector: a travessia do oposto, fê-lo atento ao outro, em alteridade, de cujo silêncio e emudecimento é o efeito.

Não queremos, com isso, invalidar uma leitura em detrimento da outra, antes estamos estimulando uma reflexão de total abertura interpretativa do romance, a qual requer uma abordagem que analise a interpretação da narrativa na história da recepção. Vê-se, em síntese, que A maçã no escuro, ao lado de A Paixão Segundo G.H., fez consolidar o nome de Lispector no “Panteão das Letras”. Recorrendo ao comentário crítico de Álvaro Lins, Nascimento declara:

A despeito da miopia (relativa, como se verá) do crítico Álvaro Lins, declarando que ela estaria entre os chamados mas não entre os escolhidos no panteão das Letras, sua reputação só faria crescer nos anos 1950 e se consolidaria a partir dos anos 1960, depois de A maçã no escuro, A paixão segundo G.H. e outros textos decisivos de nossa cultura. (NASCIMENTO, 2012, p. 280). 
Com essas leituras, do início da recepção crítica da obra de Clarice Lispector, representada, neste trabalho, por Benedito Nunes, passando pela mais recente, a de Evando Nascimento, conseguimos construir um panorama da evolução crítica dessa escritora. Evolução, aqui, não quer dizer ultrapassar uma para emergir a outra, mas abertura para novas e coerentes novidades interpretativas. Nessas políticas da interpretação, sabemos também como a reflexão crítica de Nunes se propagou e influenciou vários acadêmicos, citado em dissertações e teses nas universidades do Brasil e do Mundo. Da mesma forma, vemos os trabalhos de Nascimento ganhar um imenso fôlego, lendo pela via de temáticas atuais do ponto de vista político e das relações sociais, como se dá na referência à alteridade e à natureza, caros se fôssemos pensar a existência de uma possibilidade de leitura pelas "lentes” da biopolítica a partir da experiência de personagens, como Martim, por exemplo.

\section{CONSIDERAÇÕES FINAIS}

No Brasil, a recepção crítica da obra de Clarice Lispector alcança um maior fôlego na década de 1960, com a publicação dos romances A maçã no escuro e A Paixão Segundo G.H. No que diz respeito à crítica especializada, Benedito Nunes é um nome importante na história da recepção da ficção clariceana. Para fins cronológicos, o romance A maçã no escuro, corpus deste trabalho, foi publicado em 1961, enquanto o primeiro trabalho publicado de Nunes, em livro, data de 1966, portanto relativamente próximo do aparecimento de A maçã no escuro. Decorridos anos dos três trabalhos de Nunes, temos o aparecimento do estudo de Evando Nascimento, publicado em 2012, realizado juntamente a pesquisas realizadas a partir do pensamento do filósofo francês Jacques Derrida.

Em síntese, temos duas leituras do romance A maçã no escuro. A primeira, de Nunes, interpreta o itinerário de Martim pela via do existencialismo, cujas questões fundamentais estão arroladas sob perspectiva místico-religiosa, tendo como clave a ideia contraditória entre rebeldia e religiosidade. A segunda, de Nascimento, inserida nas interpretações mais recentes, inaugura uma perspectiva pelas vias da alteridade, nas quais se coadunam os chamados e as vocações pelo selvagem. Passando por entre as duas leituras, trata-se de interpretações coerentes, pois as ideias manifestam-se claramente a partir da própria obra. Em suma, este trabalho carrega no seu bojo a tentativa de estimular uma reflexão crítica sobre a recepção da narrativa A maçã no escuro, tendo como cerne a defesa das duas leituras, inseridas no seu devido tempo histórico.

\section{REFERÊNCIAS}

BATAILlE, G. Documents. Tradução João Camilo Penna e Marcelo Jacques de Moraes. Florianópolis: Cultura e Barbárie, 2018.

BÍBLIA SAGRADA. Tradução Antônio Pereira de Figueiredo. São Paulo: Sivadi, 2010.

DERRIDA, J. O animal que logo sou. Tradução Fábio Landa. São Paulo: Ed. UNESP, 2002.

JAUSS, H. R. A história da literatura como provocação à teoria literária. Tradução Sérgio Tellaroli. São Paulo: Ática, 1994.

LISPECTOR, C. A maçã no escuro. Rio de Janeiro: Francisco Alves, 1961. 
MACHADO, R. Helena de Oliveira. Crime e desistência nos textos de Clarice Lispector. Remate de Males, Campinas, v. 9, p. 119-130, 17 jun. 1989.

MEDEIROS, D. A. As faces melancólicas de Martim em A Maçã no escuro, de Clarice Lispector. 2014. Dissertação (Mestrado em Letras) - Universidade Estadual de Santa Cruz, Ilhéus, 2014.

NASCIMENTO, E. Derrida e a Literatura: "notas" de literatura e filosofia nos textos da desconstrução. Niterói: EdUFF, 1999.

NASCIMENTO, E. Clarice Lispector: uma literatura pensante. Rio de Janeiro: Civilização Brasileira, 2012.

NUNES, B. O mundo de Clarice Lispector (ensaio). Manaus: Governo do Estado do Amazonas, 1966.

NUNES, B. Leitura de Clarice Lispector. São Paulo: Quíron, 1973.

NUNES, B. O drama da linguagem: uma leitura de Clarice Lispector. São Paulo: Ática, 1995.

NUNES, B. Poesia e Filosofia: uma transa. In: ROHDEN, L.; PIRES, C. (org.). Filosofia e Literatura: uma relação transacional. Ijuí: Editora Unijuí, 2009. p. 17-36.

RONCADOR, S. Poéticas do empobrecimento: a escrita derradeira de Clarice. São Paulo: Annablume, 2002.

SÁ, O. de. A escritura de Clarice Lispector. Petrópolis: Vozes, 1979.

SÁ, O. de. Clarice Lispector: a travessia do oposto. 3. ed. São Paulo: Annablume, 2004.

VIEIRA, T. M. Clarice Lispector: uma leitura instigante. São Paulo: Annablume, 2004. 